\title{
König, Helmut (2020): Lüge und Täuschung in den Zeiten von Putin, Trump \& Co.
}

\author{
Bielefeld: Transcript. 358 Seiten. 29,50 $€$
}

\author{
Sebastian Schindler
}

Angenommen: 31. März 2021 / Online publiziert: 21. April 2021

(C) Der/die Autor(en) 2021

Lüge und Täuschung sind politische Phänomene. Gleichzeitig sind sie enorm bedrohlich für die Politik, wenn man unter Letzterer das gemeinsame Handeln von Menschen versteht. Helmut König hat mit seinem Buch eine tiefgehende theoretische Analyse der Rolle von Lüge und Täuschung in der Politik unserer Zeit vorgelegt. Zwei genaue und substanzielle Fallanalysen zu Trumps Amerika und Putins Russland fundieren diese Analyse. Hannah Arendt, Niccolò Machiavelli, Max Weber und Immanuel Kant dienen als theoretische Zeugin und Zeugen.

Gerade in der internationalen Politik erscheint es mitunter so, als würden Lügen und Täuschungen zur Normalität gehören. Besonders Angehörigen der sogenannten realistischen Theorieschule wird diese Ansicht zugeschrieben. Wenn Politik bloß ein Kampf um Macht ist, dann hat die Wahrheit keine Chance. Dann gilt, wie der neo-realistische Theoretiker Kenneth Waltz tatsächlich behauptet hat: ,might makes right".

König widerspricht der Auffassung, dass Lügen ein selbstverständlicher Teil der Politik sind. Das Buch beginnt zwar mit der Beschreibung einiger eklatanter Fälle von Lügen in der nationalen wie internationalen Politik, darunter etwa der Emser Depesche, die Bismarck so verfälschte, dass sie den von ihm gewünschten Krieg heraufbeschwor (S. 36). Aber der Ausnahmecharakter von Lüge und Täuschung zeigt sich gerade am Aufsehen, das solches Vorgehen unter normalen Umständen erregt. Oft ist es so, dass Lügen auch in der internationalen Politik den Lügnern zum Verhängnis werden, weil sie die Vertrauensbasis, auf deren Grundlage allein Beziehungen stattfinden können, nachhaltig stören und zerstören (S. 39). Wer einmal beim Lügen ertappt wurde, der riskiert, dass ihm niemand mehr traut. Selbst Bismarcks Lüge wurde gefeiert nur deshalb, weil sie mit einem großen politischen

S. Schindler $(\triangle)$

Ludwig-Maximilians-Universität München, München, Deutschland

E-Mail: sebastian.schindler@gsi.uni-muenchen.de 
Erfolg einherging. Nur unter diesen außergewöhnlichen Umständen konnte sie als gerechtfertigt erscheinen.

Die Zeiten haben sich geändert. Sowohl Putin als auch Trump lügen in einer Weise, die auf eine fundamentalere Transformation hinweist. Zentral ist in beiden Fällen die Annahme, dass gar nichts mehr als wahr gilt (S. 123, 205). Als Zeitgenossen dieses Vorgangs kann es für uns manchmal den Anschein haben, als wäre dies vielleicht ganz normal. Aber das ist es nicht. Es ist ein höchst destruktiver Vorgang, aus dem sich noch erhebliches Unheil zusammenbrauen kann.

Putin und Trump halten gar nichts mehr für wahr. Sie beschuldigen einerseits beständig andere der Lüge. Nichts könnte dies besser illustrieren als ein Ereignis, das erst nach der Veröffentlichung von Königs Buch geschah: das radikale Anzweifeln der Wahlergebnisse durch Donald Trump, der schon vor den Wahlen auf mögliche Fälschungen hinwies und bis heute davon auszugehen scheint, dass Joe Bidens Sieg nur durch Fälschungen möglich geworden sei.

Für die Theorie (und auch und gerade die Theorie der internationalen Beziehungen) kann man von Königs Analyse lernen, dass die Annahme, alles sei Lüge, nicht die Regel von Politik darstellt, sondern eine höchst problematische Ausnahme. In der Tat scheint genau diese Annahme zum Substrat einer Reihe von heutigen Theorien zu gehören. Man denke nicht allein an den heutigen Neorealismus. Auch eine weitverbreitete Kombination von soziologischem und rationalistischem Institutionalismus geht davon aus, dass Organisationen und andere Akteure sich nach außen prinzipiell anders darstellen, als sie innen funktionieren. Heuchelei ist demnach „organisiert“. Aber wenn Heuchelei organisiert ist, dann ist es auch die Lüge.

Königs Buch bietet Ressourcen nicht nur für ein tiefes Verständnis heutiger international wie national politischer Vorgänge, in denen Verschwörungsmythen, FakeNews-Behauptungen oder ganz allgemein der Lügen-Vorwurf eine zentrale Rolle spielen. Es bietet auch Anlass, bestimmte Arten und Weisen der theoretischen Analyse der internationalen Politik zu hinterfragen. Anstatt anzunehmen, dass Lügen weitverbreitet und „organisiert“ sind, sollte dies als eine Pathologie von politischen Beziehungen in unserer Zeit begriffen werden. Anstatt die Pathologie bloß zu beschreiben, sollten wir darüber nachdenken, wie sie überwunden werden kann. Auf dem Spiel steht, wenn wir König folgen, die Möglichkeit von Politik im Sinne gemeinsamen Handelns überhaupt.

Funding Open Access funding enabled and organized by Projekt DEAL.

Open Access Dieser Artikel wird unter der Creative Commons Namensnennung 4.0 International Lizenz veröffentlicht, welche die Nutzung, Vervielfältigung, Bearbeitung, Verbreitung und Wiedergabe in jeglichem Medium und Format erlaubt, sofern Sie den/die ursprünglichen Autor(en) und die Quelle ordnungsgemäß nennen, einen Link zur Creative Commons Lizenz beifügen und angeben, ob Änderungen vorgenommen wurden.

Die in diesem Artikel enthaltenen Bilder und sonstiges Drittmaterial unterliegen ebenfalls der genannten Creative Commons Lizenz, sofern sich aus der Abbildungslegende nichts anderes ergibt. Sofern das betreffende Material nicht unter der genannten Creative Commons Lizenz steht und die betreffende Handlung nicht nach gesetzlichen Vorschriften erlaubt ist, ist für die oben aufgeführten Weiterverwendungen des Materials die Einwilligung des jeweiligen Rechteinhabers einzuholen.

Weitere Details zur Lizenz entnehmen Sie bitte der Lizenzinformation auf http://creativecommons.org/ licenses/by/4.0/deed.de. 